\title{
Colon and Rectal Surgery
}

National Cancer Institute

\section{Source}

National Cancer Institute. Colon and Rectal Surgery. NCI Thesaurus. Code C15210.

Surgical removal of part or all of the colon and/or rectum. 